\title{
Analysis Of Rat Platelet Count After Electrical Exposure In Acute And Subacute Phase Of Burn Injury
}

$\begin{aligned} & \begin{array}{l}\text { Abstract: Electrical burns are one of the causes of important health burdens } \\ \text { throughout the world with incidences varying between } 4-18 \% \text { of all burns. }\end{array} \\ & \text { Fransiska Nooril F.P.H. } \text { In electrical burns, blood vessels are the heavily damaged tissue } \\ & \text { characterized by endothelial erosion, followed by adhesion and aggregation } \\ & \text { Laksmi Indreswari } \\ & \text { of platelet to form hemostatic plug. The screening test for assesing the } \\ & \text { formation of hemostatic plug is platelet count. Platelet count monitoring is } \\ & \text { very important during the resuscitation phase and treatment periods in } \\ & \text { severe burns, namely in acute and subacute phase of burns. The purpose of } \\ & \text { this study is to determine and to analyze about the changes in platelet count } \\ & \text { of rat after electrical exposure in acute and subacute phase of burns. The } \\ & \text { control group in this study was not given electrical exposure and rat's blood } \\ & \text { was taken directly after the adaptation process. In the other five groups, P1, } \\ & \text { P2, P3, P4 and P5 were exposed to } 140 \text { V for } 17 \text { seconds, then their blood was } \\ & \text { taken for platelet counts on days } 0,3,7,10 \text { and } 14 \text { post-exposure. The result } \\ & \text { of this study based on Post Hoc LSD test showed that there was a change of } \\ & \text { platelet platelet number after exposure in acute phase of burn injury and } \\ & \text { there was no change of platelet platelet number after exposure in burning } \\ & \text { subacute phase.. }\end{aligned}$

$\mathrm{E}$ lectrical burn injury is one of the most important health burden in the world with incidence of $4-18 \%$ of all burn injury ${ }^{1}$. Despite its relative small incidence, electric burn injury always progressively damaging tissue and is correlated with high mortality and morbidity 2 . Burn patients are prone to severe hemostatic imbalance ${ }^{3}$, with blood vessels suffer from severe damage due to its low resistance. Vascular damage starts with endothelial damage, followed by platelet aggregation and adhesion which forms platelet plug2. One of screening to detect hemostatic plug is platelet count 4 .

Acute burn phase last to 72 hours post trauma. In this phase, patients may be resuscitated. Subacute phase starts sequentially and lasts to day 14 th to 21 st. In this phase, patients may be in critical care and wound closure ${ }^{5}$.

Previously, time dependent platelet count was examined generally in all burn patients, while rarely reported specifically in electric burn

Disclosure: The authors herely declare they have no financial interest in the information discussed in this article patients. Retrospective studies reveals that platelet count was decreased in the first 3-4 days which return to normal count in 10-14 days and transient thrombocytosis in variable period of time 6 .

Platelet count monitoring is crucial in resuscitation and critical care in severe burn injury ${ }^{7}$. Researchers first correlate platelet count to patient outcome and conclude that persistent or worsening thrombocytopenia in burn patients correlates to sepsis and increasing risk of mortality 7,8 .

Prognostic value of platelet count in burn patients demands detailed investigation in electric burn patients. This study aims to investigate and analyze platelet count in electrically injured rats especially in acute and subacute phase.

\section{Method}

This is a quasi experimental study in vivo with post test only group design. This study aims to find out and analyze platelet count alteration in post electrically-injured rats during acute and subacute phase. This study was conducted in Pharmacology and 
Biomedic Laboratory and Clinical Pathology Laboratory, Faculty of Medicine Universitas Jember after ethical clearance approval from Faculty of Medicine Universitas Jember. All 24 white rats (Rattus novergicus, Wistar strain) age 10-16 weeks, weighed 250-320 grams were randomized into six groups.

Rats in intervention groups were anesthetized with $40 \mathrm{mg} / \mathrm{kgBW}$ of Ketamin and $5 \mathrm{mg} / \mathrm{kbBW}$ of xylazin intraperitonially. The rats were then electrically injured by 17 seconds of 140 volts electric current through a thin aluminum electrodes in two limbs of rats. One control group was not electrically injured and the blood from the rats of the group was collected after adaptation period. In intervention groups, blood samples were collected directly after electric injury in first intervention group, and day $3 \mathrm{rd}, 7 \mathrm{th}, 10 \mathrm{th}$, and 14 th in four other intervention groups respectively.

Platelet count was indirectly studied from blood smear preparation. All blood samples were collected by microhematocrite tube retroorbitally and smeared within two hours after collection. All blood smear preparations were methanol-fixated and Giemsa-stained. Platelet count was conducted under light microscope with immersion oil, field number 22 and 1000x magnification. Platelet was counted in 40 fields times $1000^{9}$. Two blinded examiners counted the platelets in zig-zag manner of the fields. Wistar rat normal platelet count is 800.000 $1.500 .000 / \mathrm{mm} 3$.

Table 1. Mean and Standard Deviation of platelet count. Same letter in superscript depicts insignificant mean difference

\begin{tabular}{|c|c|}
\hline Groups & Platelet Count $\left(\mathbf{m m m}^{\mathbf{3}}\right)$ \\
\hline Control Group & $962.250 \pm 153.058^{\text {abcd }}$ \\
\hline Intervention, Day-0 & $838.000 \pm 46.854^{\text {aefgh }}$ \\
\hline Intervention, Day-3 & $705.750 \pm 39.118^{\mathrm{e}}$ \\
\hline Intervention, Day-7 & $1.141 .000 \pm 467.793^{\text {bfij }}$ \\
\hline Intervention, Day-10 & $1.027 .750 \pm 193.099^{\text {cgik }}$ \\
\hline Intervention, Day-14 & $1.014 .750 \pm 245.562^{\text {dhjk }}$ \\
\hline
\end{tabular}

\section{Result}

Platelet count then was analyzed. Normality test was performed by SaphiroWilk test, and test of homogeneity using Levene's test. Platelet count data was not normally distributed and inhomogen. Data tranformation was then performed using reciprocal $(1 / n)$ transformation. One way anova was then performed with the $\mathrm{p}$ value of 0.037. Post hoc LSD test was subsequently performed and the result is presented in Table 1.

\section{Discussion}

In electric burn, the extent of tissue damage is related to voltage, current, circuit type, kind of electric injury, length of contact, and tissue conduction or resistance. Blood vessel is severely damaged due to its low resistance. Tissue damage ini blood vessel include endothelial damage and subsequent platelet adhesion and aggregation that forms platelet plug(2). One of screening to detect hemostatic plug is platelet count ${ }^{4}$.

In this study, platelet count in control group (no intervention) showed no significant difference with platelet count in intervention group day-0. This means no significant platelet count alteration directly after electric injury. Platelet is activated at least 72 hours post electric injury and functions more actively in the first 48 hours post electric injury ${ }^{10}$.

In intervention group day-3, platelet count is significantly lower (thrombocytopenia) than the control group $(p<0,05)$. Theoritically, this is due to platelet consumption from hemostatic plug activation. In burn patients, thrombocytopenia is observed in 48 hours post injury and suspected as a result of thermal injury in blood vessels and dilution effect due to fluid resuscitation ${ }^{8}$. In the study, since no fluid resuscitation was administered, the low platelet count was suspected to be the result of platelet consumption in burn wound.

Besides, another suspected pathology is electroporation phenomenon, where a direct damage of cell membrane due to direct electric current. This electric current in blood vessel 
lumen through the multiple layers of platelet membranes. The current causes the membrane protein losses its three dimensional property, distorts, and forms intramembrane pores. The process culminates in irreversible cell death due to mixed intracellular and extracellular components ${ }^{2}$.

Statistically, platelet count difference were observed between intervention groups day-7, day-10, and day-14 with the intervention

group day-3 only but not to control group. This finding is consistent to return of platelet count within normal limit after low platelet count on day-3. Previous studies showed that platelet count return within normal limit in 10-14 days with subsequent variable-length of transient thrombocytosis ${ }^{6}$.

In this study, normal platelet count was reached on day-7. Theoritically, on sixth day post electric injury, normal circulating platelet is followed by mild thrombocytosis. Platelet "refill" depends to megakariocyte sitoplasm fragmentation. Low platelet count stimulates megakariocyte forming from small acetylcholinesterase positive (SAChE +) cells. On sixth day post electric injury, production rate from megakariocyte is capable to maintain normal platelet count in circulation ${ }^{11}$.

Increase in platelet count in this study was not subsequently followed by a period of thrombocytosis, seen from normal platelet count in day-7, day-10, and day-14. This finding is consistent in several previous study in severe burn. Those studies conclude that in patients with severe thrombocytopenia on third to four days post trauma experienced no thrombocytosis ${ }^{8}$. In this study, due to specimen collecting was not continuous, we can't accurately follow platelet count day by day, especially on day-3 and day-4. One study mentioned a period of thrombocytosis rarely occurs in patients with severe thrombocytopenia and related to incidence of sepsis in burn patients 7,8 . A further study is encouraged to investigate any relation between platelet count alteration in acute and subacute phase of burn and incidence of sepsis in electrically injured rats.
First limitation of this study was no platelet count performed in the end of acute phase. This makes the length of thrombocytopenia period impossible to be concluded. Another limitation is direct counting of platelet through blood smear test. This method requires skillful personel in smearing blood sample. Subjectivity is relative high and precision is hard to achieve. Common pitfalls are inspecting difference between platelet and stain particle, inequality in platelet distribution, and method of reading the fields ${ }^{12}$. We suggest further study to use automatic animal hematology analyzer to minimize error.

\section{Conclusion}

We observed platelet count difference in acute phase of electric burn injury and no difference in platelet count difference in subacute phase of electric burn injury.

\section{Bibliography}

1. Tiryaki C, Haksal MC, Yazicioglu MB, Ciftci A, Esen 0, Turgut HT, et al. Factors affecting mortality among victims of electrical burns. Ulus Travma Acil Cerrahi Derg. Turkey; 2017 May;23(3):223-9.

2. Moenadjat Y. Luka Bakar: Masalah dan Tatalaksananya. Edisi Keem. Jakarta: Badan Penerbit FKUI; 2009.

3. Pavic M, Milevoj L. Platelet count monitoring in burn patients. Biochem Medica. 2007;17(2):212-9.

4. Bakta I. Hematologi Klinik Ringkas. Jakarta: EGC; 2006.

5. Noer MS. Penanganan Luka Bakar Akut. In: Noer MS, Saputro ID, Perdanakusuma DS, editors. Penanganan Luka Bakar. Surabaya: Airlangga University Press; 2006. p. 3-22.

6. Elisabeth Marck R, Montagne HL, Tuinebreijer WE, Breederveld RS. Time course of thrombocytes in burn patients and its predictive value for outcome. Burns. 2013;39(4):714-22.

7. Kamble PA, Kamble MK, Kamble AT, Abhishek P, Pandey P. Platelet Count: A Prognostic Indicator in Early Detection of Post Burn Septicemia. Eur J Biomed Pharm Sci. 2017;4(7):510-2. 
8. Warner P, Fields AL, Braun LC, James LE, Bailey JK, Yakuboff KP, et al. Thrombocytopenia in the pediatric burn patient. J Burn Care Res. England; 2011;32(3):410-4.

9. Gandasoebrata R. Penuntun Laboratorium Klinis. Jakarta: Dian Rakyat; 2013.

10. Jacoby RC, Owings JT, Holmes J, Battistella FD, Gosselin RC, Paglieroni TG. Platelet activation and function after trauma. J Trauma. United States; 2001 Oct;51(4):639-47.

11. Kalmas G, Guest M, Bessman J, Herndon D. Response of small acetylcholinesterase positive cells, megakaryocytes and platelets to burn injury. Ann New York Acad Sci. 1990;

12. Sacher R, McPherson R. Tinjauan Klinis Hasil Pemeriksaan Laboratorium. 11th Ed. Jakarta: EGC; 2004. 